\title{
EDITORIAL
}

\section{The Mental Strategies of Surgeons: A Primer - Part II}

\author{
Curt Tribble, MD
}

Division of Cardiac Surgery, University of Virginia, Charlottesville, VA, USA

\author{
Part I \\ Introduction \\ Foundations \\ The Hardy Personality \\ Preparation \\ Decision Making
}

\section{Part II}

Vision

Awareness \& Focus

Reflection \& Analysis

Leadership

Independence

\section{INTRODUCTION}

In this two part essay, we have addressed the mental skills and strategies of surgeons that students interested in a career in Surgery and residents training in this realm should have or acquire during their trajectories on their career paths. In Part I of this treatise, we covered the concepts of foundations, the hardy personality, preparation, and decision making. In Part II, we will address the concepts of vision, awareness and focus, reflection and analysis, leadership, and independence.

\section{VISION}

I skate to where the puck is going to be, not where it bas been. -Wayne Gretsky

A young faculty member in our Department of Surgery once made the observation that, while it seemed there was a fairly broad consensus amongst the residents as to who the best surgeons in the Department were, it also seemed to him, based on watching these surgeons operate himself, that it was not apparent that they seemed any more facile or adept than others who were not considered to be as 'good.' This person asked me if I could explain that apparent discrepancy. While

Correspondence: Curt Tribble, MD, Professor of Cardiothoracic Surgery, University of Virginia Health System, Division of Cardiac Surgery, Box 800679, Charlottesville, VA 22908; 434-243-9250 (e-mail: ctribble@virginia.edu).
I had not thought about that issue before, I suggested that what likely set these well-regarded surgeons apart was vision. I believe that the attribute which distinguishes the best surgeons from others is that they are able to hold in their mind's eye a vision of what it is that they want to have happen in an operation and that they efficiently proceed with their operations with that vision held firmly in mind.

\section{A Sculptor at Work \\ Humans have the unique ability to keep in mind what is not before their eye ... Visualizing far ahead, we see our quarry, even as it recedes over the hills and into the mists. Those ancient bunters who bad the longest vision - the most imagination - were the ones who persisted the longest on the trail and, therefore, were the ones who left the most descendants. - Bernd Heinrich, The Endurance Predator}

Around the time that I was mulling over the answer to my colleague's question, I operated on a local sculptor, David Breeden, who had achieved a degree of regional renown, working with soapstone found only in this area, one lode of which was on his family's property. I had talked to him about how he created his 'masterpieces,' and he, not surprisingly, at least in retrospect, noted that he pictured what he wanted to create and merely removed the stone that "didn't belong." I told him that I thought that his approach was quite similar to how surgeons move through operations, having an image in their minds of what they want to 'create' during a given operation. Therefore, I have come to think, and teach, that a surgeon needs to be like a sculptor at work, envisioning what is to be created from a block of stone.

I think many surgeons, especially those in training, approach their operations thinking they will just 'figure it out' as they go along and do not really have a clear vision of what they want to accomplish. I think that this approach can hold a surgeon back, making them slower and less efficient, but also, and more importantly, interfering with the end result. I think they simply must have a vision of what they are trying to accomplish in order to perform at their best.

Obviously, a surgical resident, at the beginning of training, has a less focused image of what they want to accomplish in a given operation, and they may not understand quite how to gain this vision. Obviously, one can look at books, do dissections in the anatomy lab, and watch videos. An even better strategy is to observe others operating. The development of vision requires constant reflection and analysis. However, the real incorporation of vision into one's practice will come only with experience. 


\section{Target Fixation}

When you have played basketball for a while, you don't need to look at the basket ... You develop a sense of where you are. -Bill Bradley, A Sense of Where You Are

Even when one has a clear 'vision' of one's objectives when performing surgical operations, there are pitfalls that must be guarded against. It has been said that our conscious minds are at the mercy of probabilistic processes. We can understand this issue when looking at optical illusions. A related pitfall is known as target fixation, a concept well-known to pilots. Military pilots have been known to be so 'locked in' on a target that they fly right into it. [Robert Shaw. 1985]

On a related note, all of us who have been snowboarders, skiers, and mountain bikers know the old saying: "You hit what you look at, so you must always focus on the empty spaces." I have often thought that this admonition is analogous to the anatomical planes of dissection that are important to understand in many operations.

\section{AWARENESS \& FOCUS}

Most people struggle to be present. Michael fordan is a mystic [because] he was never anywhere else. His gift was that he was completely present, and that was the separator. -Mark Vancil, Rare Air

Surgeons, when operating, must be able to keep an intense focus on the procedure that they are doing while also being present, maintaining an awareness of what is going on in the operating room around them. Understanding that it can be challenging to do both at once, one needs to try to achieve a rhythm between utter, intense focus and a more general awareness of everything else that is going on in the operating room.

\section{Focus, then Feel}

Between stimulus and response there is a space. In that space is our power to choose our response. In our response lies our growth and our freedom. - Viktor E. Frankl

I had an epiphany about this balance of awareness and focus, as well as the juggling of stimulus and response, early in my own career, as I dealt with an emergency coronary artery bypass operation. As I was walking out of an operating room having just completed a fairly routine case, one of my senior cardiology colleagues swept around a corner, dressed in his street clothes and a white coat, pulling a stretcher with a patient on it. He asked which operating room was open, and someone pointed at one of the rooms that was, indeed, empty. He then saw me walking down that hall and said "this man needs a coronary bypass operation, right now!" I asked what had happened, and he said that the patient had been in the cath lab for a balloon angioplasty of his left anterior descending coronary artery and that this artery had become occluded, causing ongoing ischemic injury to his heart. I immediately understood the gravity of the situation, of course, but I also knew that it would be challenging to

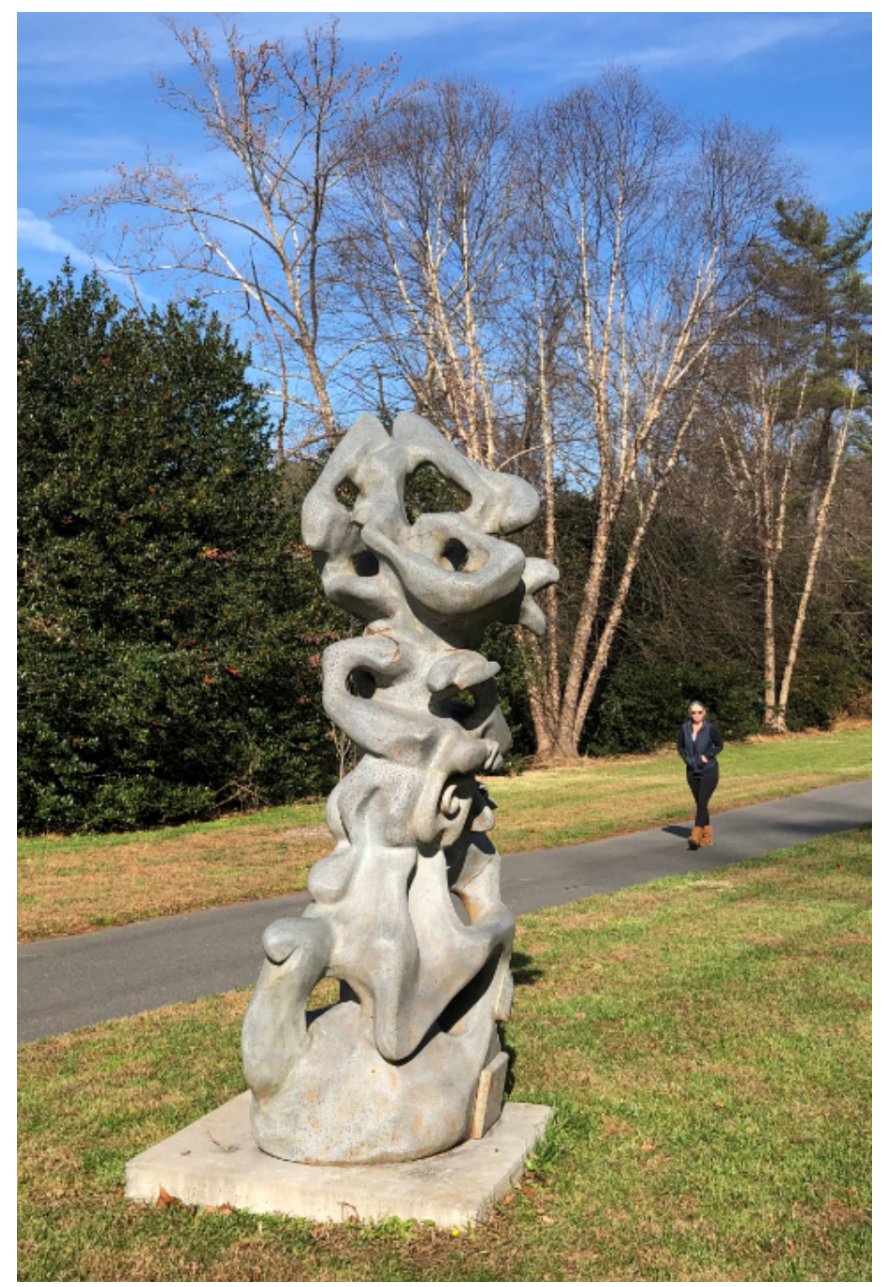

Oasis, 1990, by David Breeden

round up an entire operating room team, including anesthesiologists, perfusionists, nurses, and assistants on such short notice. Fortunately, many of these people flocked to the room to try to begin dealing with this emergency, while I was trying to clear my mind of the operation I had just finished doing and to sort out what I needed to do for this patient. However, just as I was beginning to gather my wits, my cardiology colleague said, "Oh, by the way, this man was recently the mayor, and you will likely need to talk to the reporters after you're done." I could have done without that unnecessary, additional information! I was relieved when one of my favorite senior residents ran into the room, asking how he could help.

As we got started, another faculty surgeon barged into the room and accosted the resident who, evidently, was supposed to be waiting in another room for a different patient to arrive. I realized at that moment that I needed to consciously regain control of my emotions, and I had an epiphany. I pictured myself swimming using a breast stroke, which requires alternating between having one's face in the water with coming up to breathe. As I envisioned putting my face underwater, I blocked out all the mayhem in the room around me so that I 
could focus precisely and intently on the tasks at hand. As I envisioned coming up for air, I was able to return my attention to all that was going on in that room in order to help coordinate our efforts. I found that this cycling between complete focus and general awareness allowed me to both move along with the necessary steps of the operation, while keeping everyone else in the room organized and on the same page. My colleague, Doug Newburg, has described this cycling as a process of 'focus then feel.' Thankfully, the patient did very well, and I was grateful to also be able to dodge those reporters afterwards! At the end of that day, I had learned a valuable lesson about how to cycle effectively and efficiently between the complete focus and the general awareness that are necessary in most cardiac surgical operations.

\section{The Yarn on the Sails}

I believe that I learned as much about surgery, and the teaching of surgery, from learning to race sailboats and from teaching others how to sail and race them as from any other one thing that I have done. [Falk, 1973] First of all, sailing, like surgery, is rarely something that people grow up knowing much about. People are just not born knowing how to sail nor how to operate. Second, sailing requires making many decisions in rapid succession to deal with constantly changing conditions, and these conditions are most rapidly changing when racing, with constantly changing wind, course direction, and the maneuvering of one's opponents. Said succinctly, whatever you were doing a few minutes prior is now, likely, not quite right. Furthermore, the number of disparate issues to be considered under these conditions is considerable, from the setting of the sails to the heel (side to side) and the balance (fore to aft) of the boat, as well as the position of the rudder, while determining the course to be set.

We sometimes use the term 'the yarn on the sails' to describe creating a condition of optimal flow of the wind over
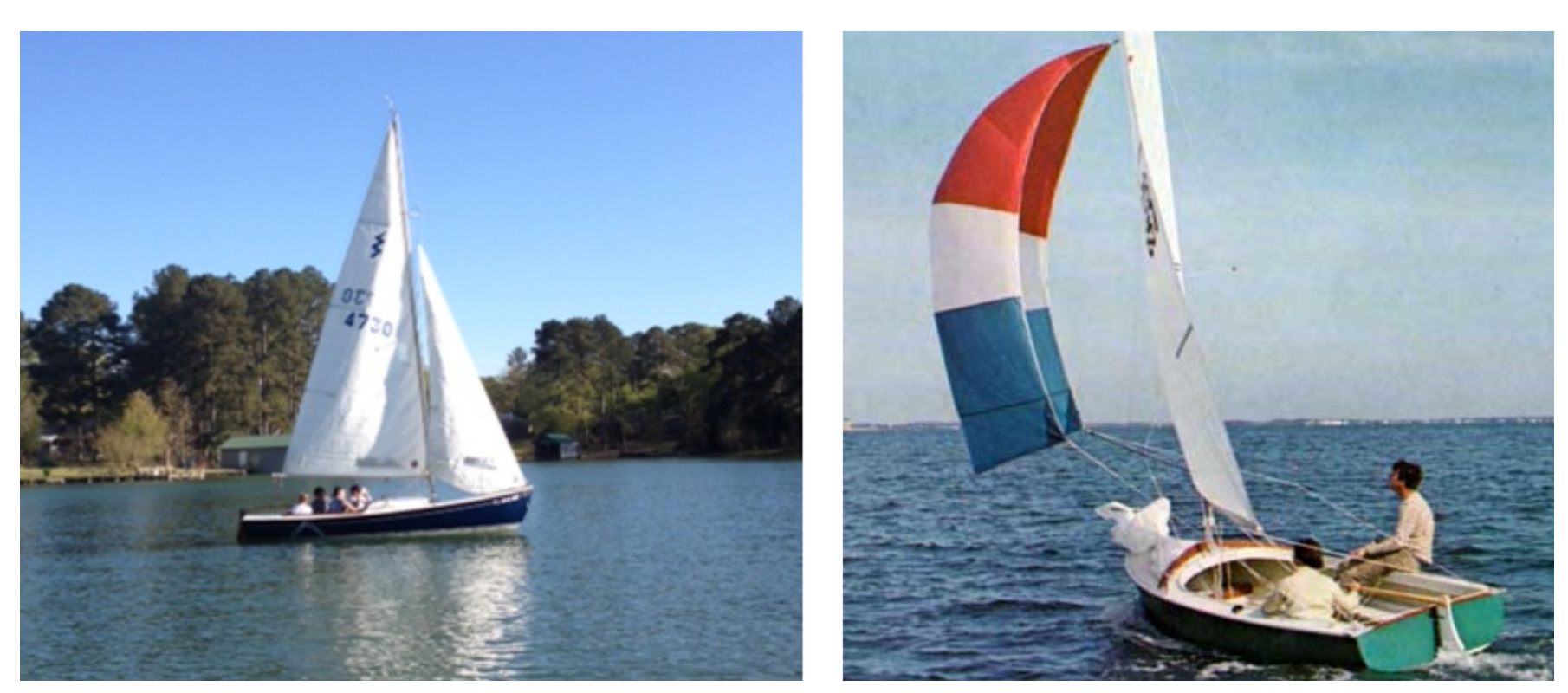

the sails, and this concept can also describe how one should lead a surgical team during a complex operation, thinking of many different conditions, unifying the efforts of all 'in the crew,' with constant awareness of ever changing information and conditions. Teaching the use of the mental checklists that must be reviewed constantly when sailing, and especially when racing, is very analogous to teaching residents how to think in the operating room during surgical operations, especially complex, challenging, or unfamiliar ones.

\section{Dealing with 'Sea Sickness'}

I have often used another nautical concept, sea sickness, to describe the feeling of trying to control what is happening during a challenging operation. It is said that seasickness is caused by the discrepancy between two sensory inputs; that is, between what one sees and what one feels when being tossed around in a boat in rough water. A similar feeling occurs when one is teaching in the operating room and having to deal with the discrepancy between what you, as the leader of the surgical team, envision happening and what is actually happening. You must train yourself to deal with this 'sea sickness' and to be able to draw those two visions back into alignment.

\section{Maintaining General Awareness}

Al grew tense over the wheel. A little rattle had developed in the engine. He speeded up and the rattle increased. He retarded his spark and listened. The rattle increased to a metallic pounding. Al blew his horn and pulled the car to the side of the road. - John Steinbeck, The Grapes of Wrath

Any one of us who has maintained and driven an old car can relate to Steinbeck's description of Al Joad's awareness of the feel of a car 'in distress.' Every shake, rattle, and hum has an implication to be taken into account. Examples in an

Two sailboats I have owned and raced, both made by O’Day. 
operating room include paying attention to conversations, tone of voice, sounds of the cardiopulmonary bypass machine, or the crinkle of a bag of Hetastarch (a 'stealth' anticoagulant) being opened at the head of the operating table. [Cope]. Some have called this kind of awareness 'court sense,' a skill or ability that has been said to have defined the greatness of both Larry Bird and Magic Johnson, in their heyday as NBA stars. Martial arts practitioners call this type of awareness 'mushin,' which describes a 'wider vision' of what is happening around a fighter in a martial arts battle.

\section{Living Life in a Coffee Can}

The intermittent and necessary narrowing of one's vision during a cardiac operation is sometimes described as 'living life in a coffee can' which is an allusion to the narrowed focus of the limited field of view when operating with magnifying loupes. However, you must be able to develop a rhythm between absolute focus and general awareness, as you give your all to the task at hand.

\section{Developing a 'Surgical Conscience'}

It is best if you are able to maintain several layers of unconscious thought about what is being done during an operation. One layer is a type of 'surgical conscience' that follows along behind what you are doing, double checking what has been done. One way to think of these 'levels' is to picture people swimming along at different levels in the ocean, perhaps while scuba diving. The person who is higher off the ocean floor has a broader perspective than those close to the bottom, and the person above can see more things around them than can those closer to the bottom. Sometimes the primary surgeon will have to shift back and forth between these various levels of awareness in order to pay proper attention to all the pertinent issues during a surgical operation.

\section{REFLECTION AND ANALYSIS}

He concluded that, far more than technical skills or intelligence, what was necessary for success was ..... a practical-minded obsession with the possibility and the consequences of failure. - Malcolm Gladwell, The Physical Genius

One of the most important aspects of learning to be a master surgeon is to learn how to reflect upon what you have done, to analyze your results, and to learn from everything you do. One of the first steps in dealing with something that has not gone the way you want is to realize that you will generally feel a sense of loss, or even grief, as described by Dr. Elisabeth Kübler-Ross in her famous book, On Death and Dying. [Kubler-Ross] Denial and anger, bargaining and depression, and acceptance and hope are the stages that she observed terminally ill patients going through in dealing with their conditions. I have observed that these stages are also experienced by anyone dealing with any type of loss or grief. People will often vacillate back and forth between these various stages, but eventually as they work through them, they will come to a point of acceptance, which can allow them to look forward instead of looking back. These are the same feelings that many performers will have when dealing with a suboptimal outcome.

\section{The Most Important Hour of the Week \\ We don't learn from experience. We learn from reflecting on experience. - John Dewey, 1859-1952}

The process of dealing with bad outcomes has likely been formalized as much in the discipline of Surgery as in any other realm of medicine. Virtually every Department of Surgery has a weekly conference known as 'Death and Complications Conference' or 'Morbidity and Mortality Conference.' The M\&M conference has frequently been called 'the most important hour of the week,' and I most certainly agree with that designation. These conferences are formal reviews of complications, deaths, or any other suboptimal outcome that occurred. While this process is formalized, it is one for which our surgical residents need guidance in order to participate optimally and to take the lessons learned in these conferences back to their own clinical practices. [Tribble, 2016]

It isn't reasonable to ask that we achieve perfection ... What is reasonable is to ask that we never cease to aim for it. - Atul Gawande, 1999

One of the things that we teach our residents is that the goal of the conference is to search for the lessons and not for the guilty. We ask them to consider what might have been done differently or better. We ask that they teach others some lessons learned from the case under discussion. We even encourage them to consider creating a 'wish list,' whereby they can think about what they wish might have been different, even if some of these issues were not under their control. For instance, they might wish that a patient would have been younger or healthier or that the patient might have gotten to the hospital sooner. This type of 'wishful thinking' can be helpful on occasion when it may seem that the bad outcome was inevitable, or at least nearly so.

\section{Catharsis from Learning}

The overall approach to reviewing and learning from suboptimal outcomes can be useful because the goal of every discussion of this sort is to learn to be able to approach similar situations better in the future. There is also an element of catharsis that can be achieved from this type of analysis. Often, people will carry around the bad feelings of some untoward result for a long time without really dealing with them. With the emphasis on shared learning and with support from a group of peers, it is possible to unload some of the feelings one might have had and to go forward, better armed for future, analogous situations. In a sense, given that nobody is perfect and that nature is at times fickle, bad outcomes are bound to occur, and the surgeon or physician really only has two choices when these things happen. One option is to learn all the lessons that can be learned, forgive themselves and the others involved, and carry on. The other alternative is to get out of medicine altogether. Some do choose the latter, but if 
all physicians and surgeons were to choose that option, we would not have enough doctors!

\section{Establishing a Rhythm of Review}

The immediate review of one's performance requires that one analyze it, learn from it, remember the lessons, forgive one's self and others for whatever parts of that performance were sub-optimal, suppress or deal with the emotional side of the event, refocus on what needs to be done next, and go on. There is an implication here of establishing a rhythm of doing, analyzing, and doing again. I learned this lesson of needing to do this immediate review in the setting of the need for a rhythmical approach to performance as I learned how to do coronary anastomoses.

Often, certain coronary anastomoses will be the ones in which a person's life may hang in the balance. This situation can certainly raise the anxiety that one feels when doing this kind of work. As I was learning how to do these operations myself, I would be in the mode of putting in stitch after stitch and, often, be feeling pretty good about the way things were going. Not infrequently, however, my attending surgeon would say that the stitch was too deep or too wide and that my stitch, if left alone, would be a 'widow maker' stitch. One can certainly get rattled by that sort of an assertion! On the one hand, you might feel the urge to argue, while on the other hand you may feel hurt or sad that this criticism had been levelled at you. However, your only appropriate choice is to look at the stitch, see what it was that the attending surgeon thought was not quite right, do it over, see if you could make it better, and move on.

However, if you are not learning from each of these stitches and each of these comments, you might never improve. Of course, one must constantly improve and get better. So I learned to get into a rhythm in which I would place the stitch, analyze it, listen to any comments that were made, learn from them, remember the point made, get rid of any feelings I had about the stitch itself, suppress that thought, and, then, refocus for the next stitch, which was often even more important than the one I had just done. I have subsequently learned to apply this same approach to many other things, whether it be giving presentations, learning people's names, shooting a basketball in a game, learning how to snowboard, or any one of many, many other tasks or activities.

\section{The Value of Minimizing and Maximizing 'Windows'}

The second stage of optimal learning in these kinds of situations is to conduct some form of later review. I have often thought that this process is analogous to minimizing and maximizing windows in a computer program. This concept of minimizing a window, which can later be reopened, is very valuable when one is performing in the moment. This concept is all the more valuable in situations where one must learn from what one is doing and in which the time constraints are considerable, such as in a coronary artery bypass operation.

One of the ways I try to incorporate the concept of 'maximizing the window' later is to write out my reflections at the end of an operation or after some subsequent discussion. Frequently I will discuss a case I have done with a resident or a partner, and I will have some additional ideas or understanding of what we have done or might have done. When this occurs, I make a note in my pocket notebook to write out or dictate my thoughts about the subject at a later time. I have found, over the years, that the most efficient and effective way to create these notes initially is to write them in notebooks, such as a Moleskine notebook. Occasionally, I will come to think that these reflections have evolved enough that I will dictate or type them up and keep them in my techniques notebooks. In this way, I am able to reflect more fully later on things that I have done. This type of contemplative review is very valuable, both for improving in one's work and for enhancing one's peace of mind.

\section{LEADERSHIP AND TEAMWORK}

Music, basketball, it's all the same. The elements of life, the elements of being on a team, the elements of being in a band, include creativity, imagination, sacrifice, discipline, order, purpose, bope, opportunity, loyalty, gratitude. —Bill Walton

While every physician has to have at least some leadership skills, it is apparent that surgeons must have more leadership skills than most physicians. After all, surgeons are virtually always leading teams of health care providers, often teams that are quite large and diverse. Most physicians will have had some experience with, or even training in, leadership by the time they enter medical school. Many obtain leadership experience through student government, sports teams, jobs, Scout troops, musical groups, or even in some structured learning environment, such as business or leadership classes. Furthermore, there are many books written on leadership, ranging from those on leadership in the military to those on leadership in the business world. However, regardless of one's prior experience or education in the realm of leadership, these skills are an essential part of training in, and in the practice of, Surgery. I will dwell here on five aspects of leadership that I have found helpful:

- Always being honest

- Understanding the language of leadership

- Recognizing the dignity of difference

- Leading from the front

- Committing to the concept of servant leadership

\section{Honesty in Leadership}

Everything is your fault, if you're any damn good. - Ernest Hemingway

A surgeon (or any leader) must be a leader of character. While leaders in any realm will generally have all of the qualities we normally associate with leaders, such as ambition, confidence, courage, intelligence, eloquence, responsibility, creativity, and compassion, there is one thing that many too frequently overlook and that is that a leader of character must be absolutely trustworthy, even under duress, who can be depended on to put the needs of others above their own personal considerations, not just occasionally or when the spirit moves them, but in every instance. [Donnithorne] 


\section{The Language of Leadership}

I'll tell you what leadership is. It's persuasion - and conciliation - and education - and patience. It's long, slow, tough work. That's the only kind of leadership I know - or believe in - or will practice. —Dwight D. Eisenhower

It is important to understand the language of leadership. Studies have shown that language with increased grammatical nuances, third person plural words, impersonal pronouns, the past tense, and words conveying a tentative mindset can all lead to suboptimal outcomes. In contrast, it may be more effective to use the active voice rather than the passive voice. For example, instead of saying something like 'this or that happened,' choose instead to say 'we did this' or 'we are going to do that.'

Another important aspect of the language of performance is the hierarchy of language. As Atul Gawande has pointed out in some of his writings, we must recognize the need to move from "a culture of cowboys to a culture of pit crews." [Gawande, 2011] Malcolm Gladwell, in his book Outliers, reviewed the excessive crash rates, in the past, of airliners piloted by Korean air crews. [Gladwell, [2008] An analysis of these crashes revealed that these crews suffered from the inherent hierarchal structure of the Korean language. Crew members, it was discovered, had struggled to overcome the hierarchy of their native language in stressful situations. Once this issue was recognized, the language of air travel for the Korean crews became English, a language much less inherently hierarchal. We would do well to recognize similar barriers to optimal performance in our own working environments and to seek ways to maximize input from all of our team members. One specific way to start this process of breaking down hierarchal barriers is to name everyone in the room by their first name, including the team leader, during the time out process that precedes every procedure. Throughout my career, I have always introduced myself to my surgical team members by my first name, to optimize communication. [Tribble. The Way We Talk, 2014]

\section{The Dignity of Difference}

I have learned some crucial leadership and teambuilding principles from my friend and colleague, Doug Newburg, who has a $\mathrm{PhD}$ in Sports Psychology. He teaches that there are three primary principles in leading complex teams, particularly those composed of elite performers, which has, certainly, throughout my own career, included large operating teams. Dr. Newburg espouses these three key leadership principles:

- Helping people feel that they belong.

- Making sure people feel listened to and heard

- Getting it right, without making others feel wrong.

There is no doubt that every person on a surgical team counts. The surgeon must be aware of even subtle psychological differences that might be present in some of the team members and help each of these people contribute while avoiding letting these differences interfere with the team's overall function. If any one of these very important people does not do their job, the operation may not turn out well. The leader must also recognize that everyone must understand what is happening, especially on a complicated or unusual operation, and must take responsibility for teaching their team members what they need to know in order to provide effective help for those doing the operations.

\section{Leading from the Front}

Another aspect of leadership is, by definition, looking and planning ahead. I recently became aware of a type of leadership that is quite analogous to a surgeon leading a large operating room team through a complex operation. That analogous leader is the conductor of an orchestra. This analogy became apparent to me when I heard the recently retired conductor of the symphony orchestra at the University of Virginia, Kate Tamarkin, speak at an annual reception for new members of the School of Medicine's Academy of Distinguished Educators. Dr. Tamarkin described how a conductor must 'stay ahead' of the musicians actually playing their instruments. That is, the conductor has to be "playing the music in her head' prior to actually hearing the musicians play their parts. This ability to plan ahead and 'to see further than others' is a key aspect of leadership in the operating room, and it is a skill that must be learned by our trainees as they mature as surgeons. The type of planning that goes into preparing for any operation is complex but well understood. The type of leadership that is analogous to the conductor of an orchestra is not as obvious but is equally important.

\section{Being a Servant Leader}

The least and most that can be said about Lawrence is that he is a good man. This 'good' is something that can be understood by a child or a savage or any simple minded person. It is just a feeling you get from him, the feeling that here is a man with great powers, a man who could make most men do exactly whatever he desires, but yet one who would never use his powers, from respect for the other man's freedom. - Robert Graves, in Lawrence and the Arabs

I believe that the most effective leaders are 'servant leaders.' In other words, to be a successful leader you have to put a priority on respecting and valuing your people, your team members. An example of this concept is the US Marine Corps tradition that 'the officers eat last.' I had a noteworthy experience in my own training that illustrates this concept of being a servant leader. As I started into a three month stint in the thoracic and cardiovascular intensive care unit, I was well aware that the nurses not only were very experienced and knowledgeable but they also knew and did things that I needed to know about. I told them, on my first day of that rotation, that I wanted to understand as much as possible about what they did for our patients on a day to day basis. They reminded me frequently of this assertion, asking me to help change bed sheets, move patients in and out of bed, or do other chores that were vital to good patient care that might have been considered menial by some. I always pitched in when asked. At the end of those three months they surprised me by giving me an 'Honorary RN' plaque. I still consider that 'award' to be one of my favorites. This recognition certainly reminded me, 
in a colorful way, how much our team members appreciate a collaborative, service oriented attitude.

\section{Genius Loci}

Education is not the filling of a pail, but the lighting of a fire. —William Butler Yeats

Genius loci, is a Latin term meaning 'the spirit of a place.' I have come to believe that the single most important goal or duty of leaders is to create a culture, or a spirit, of inclusiveness and collaboration. A team is only as strong as its weakest link, and a good leader must be able to inspire every team member to perform at their best, while believing in the mission of the team. This concept of the spirit of a place is likely one of the most important characteristics of an institution or a group. And, this type of culture starts at the top, with the leaders of a team or organization.

\section{INDEPENDENCE}

I've been waiting for this moment for all my life ... -Phil Collins, In the Air Tonight

Obviously, the goal of a surgical training program is to make independent surgeons of our trainees. They come into the training environment unable to be very independent, and they must leave ready to be on their own. I sometimes think of that evolution as being analogous to young birds learning how to fly because both require emulation, experimentation, and constant learning. When our trainees have reached this point in their training, we recognize that they have earned the freedom to be independent surgeons. They have learned, after thirty years of formal education and tens of thousands of hours of education and training, to balance their freedom to perform as surgeons with the responsibility for managing the quality of their performance. They are ready to fly.

\section{SUMMARY}

The mental strategies that surgeons need to understand and acquire in their training are, on the one hand, crucial to successful performance, while, on the other hand, are often not taught as explicitly as one might expect in training programs. The goal of this treatise is to provide a summary of these important concepts in an attempt to make them at least a bit more accessible, both to the trainees, as they attempt to acquire them, and to their mentors, as they work to convey them.

\section{REFERENCES}

Gretsky W. https://www.goalcast.com/2017/12/30/wayne-gretzky-quotes/ (Accessed 11-25-2020)

Heinrich, B. 2004. Endurance Predator. Outside Magazine. https://www. outsideonline.com/2418782/keeping-colorado-chill-tubing-downtowndenver (Accessed 11-23-2020)
David Breeden. http://www.biscuitrun.com/ (Accessed 11-25-20)

McPhee J. 1999. A Sense of Where You Are. Farrar, Straus and Giroux. New York.

Shaw R. 1985. Fighter Combat: Tactics and Maneuvering. Naval Institute Press.

Vancil M. 1993. Rare Air: Michael on Michael. HarperCollins. New York.

Frankl V. https://www.goodreads.com/author/quotes/2782.Viktor_E_ Frankl?page=2 (Accessed 11-23-20)

Falk, Stephen. 1973. The Fundamentals of Sailboat Racing. St. Martin's Press, New York, New York.

Steinbeck J. 1939. The Grapes of Wrath. Penguin Group. New York.

Cope J, Banks D, Mauney et al. 1997. Intraoperative Hetastarch Infusion Impairs Hemostasis after Cardiac Operations. Ann Thorac Surg 63:78-83.

Gladwell M. 1999. The Physical Genius. The New Yorker. Conde Nast, New York.

Kubler-Ross E. 1969. On Death and Dying. Scribner, New York.

Dewey J. https://www.goodreads.com/author/quotes/42738.John_Dewey (Accessed 11-23-20)

Tribble C. 2016. A Practical Minded Obsession with the Possibility and Consequence of Failure. Heart Surgery Forum 19(1): E001-4.

Gawande A. 1999. When Doctors Make Mistakes. The New Yorker. Conde Nast, New York.

Walton W. Bill Walton, Fire on the Mountain. https://www.gq.com/ story/bill-walton-fire-on-the-mountain (Accessed 11-23-20)

https://www.quotetab.com/quote/by-ernest-hemingway-everything-is-yourfault-if-youre-any-damn-good (Accessed 11-25-20)

Donnithorne L. 1993. The West Point Way of Leadership. Doubleday. New York

Eisenhower D. https://www.azquotes.com/quote/1384058 (Accessed 11-25-20)

Gawande A. 2011. Cowboys and Pit Crews. The New Yorker. Conde Nast, New York.

Gladwell M. 2008. Outliers: The Story of Success. Little, Brown and Company. New York.

Tribble C, Merrill W. 2014. The Way We Talk is the Way We Teach. J Thorac Cardiovasc Surg 147: 1155-9.

Graves, R. 1927. Lawrence and the Arabs. Doubleday Doran, Co Inc. New York.

https://www.brainyquote.com/quotes/william_butler_yeats_101244 (Accessed 11-25-20)

Collins P. 1980. In the Air Tonight. Virgin Atlantic. atlanticrecords.com

\section{ADDITIONAL REFERENCES}

Junger, Sebastian. 2016. Tribe: On Homecoming and Belonging. Hachette Book Group, Inc. New York.

Stephens E, Dearani J. 2020. On Becoming a Master Surgeon: Role Models, Mentorship, Coaching, and Apprenticeship. Ann Thor Surg, in press. https://doi.org/10.1016/j.athoracsur.2020.06.061

Newburg, D. 2006. The Most Important Lesson No One Ever Taught Me. Xlibris Corporation LLC. Bloomington, IN 
McRaven W. 2017. Make Your Bed: Little Things that Can Change Your Life ... and Maybe the World. Grand Central Publishing. New York.

Marvil P, Tribble C. 2017. Lessons from Crew Resource Management for Cardiac Surgeons. The Heart Surgery Forum 20: E077-EO81.

Henderson, Richard. 1972. Sea Sense. International Marine Publishing Company. Camden, Maine.

\section{ACKNOWLEDGEMENTS}

My primary acknowledgement is to my father, David E. Tribble, MD, who died during the time I was writing this essay. My father was a Thoracic Surgeon who had six sons, three of whom are surgeons practicing some combination of Thoracic, Cardiac, Vascular, and General Surgery. While our father never pushed any of us to go into medicine or, specifically, into a field of Surgery, it is impossible not to acknowledge his influence, both on our choice of careers and on how we have approached the challenges inherent in them. Many of the concepts and tenets included in this essay were surely discussed regularly by the four of us around our family's tables and porches. My father will be remembered by, in addition to his six sons, 17 grandchildren and 23 great-grandchildren (so far). One of my friends may have summarized these sentiments the best by writing: "I love thinking of your Dad as an inspiration in your life, knowing that you and he had, and always will have, each other."

I will next acknowledge the enduring influence of my friend, colleague, and confidant, Doug Newburg, PhD. Thousands of hours of conversations and working together over the last three decades have influenced and enhanced every part of this essay. I would also like to thank two of my excellent medical student advisors, Haley Jenkins and James Keiler, both of whom will, I am confident, be leaders and educators in Surgery.

The photographs included in this essay were created by Ben Tribble.

Finally, I will pay homage to a few of the extraordinary mentors, teachers, and colleagues that I have learned from and been inspired by including Mary Coleman, Agnes Caughman, Tex Leveritt, Jim Skinner, Neal Prater, Nolan Carter, Stan Nolan, Scott Jones, John Kern, Bob Hannan, Marc Mitchell, and Walter Merrill, as well as many others. 